\title{
Case series of cultivated oral mucosa epithelium transplantation for limbal stem cell failure: experience in Malaysia
}

\author{
Kah Lay Oh${ }^{1}$, Aida Zahidin , Umi Kalthum Md Noh', Safinaz Mohd \\ Khialdin', Ghee Chien Ooi ${ }^{2}$, Kong Yong Then ${ }^{3}$ \\ 'Department of Ophthalmology, Universiti Kebangsaan Malaysia Medical \\ Centre, Kuala Lumpur, Malaysia; ${ }^{2}$ CryoCord Sdn. Bhd., Malaysia; ${ }^{3}$ International \\ Specialist Eye Centre, Kuala Lumpur, Malaysia
}

\begin{abstract}
Purpose: To report a case series of seven eyes (six patients) with severe limbal stem cell failure who underwent cultivated oral mucosa epithelium transplantation (COMET) in preparation for corneal transplant surgery and assess the change in visual acuity postoperatively.

Design: Case series.

Methods: A retrospective analysis of an interventional case series of six patients with severe limbal stem cell deficiency who underwent COMET between 2012 and 2015 was performed. Six eyes had COMET followed by corneal transplant, and one eye had corneal transplant preceding COMET. The change in the visual acuity after operation was evaluated.

Results: A total of six patients with seven eyes were studied. All of them had severe ocular surface disease with limbal stem cell deficiency (LSCD) secondary to chemical injury (five eyes), SJS (one eye), and severe ocular rosacea (one eye). Four eyes had improvements in visual acuity, two of which achieved best corrected visual acuity (BCVA) of 6/12.

Conclusion: The use of COMET helps to optimize the ocular surface in severe LSCD for further corneal transplant surgeries. It has helped to improve the graft uptake and subsequent visual improvement, especially in chronic chemical burn cases.
\end{abstract}

Keywords: acne rosacea, chemical injury, corneal transplant, cultivated oral mucosa epithelial transplantation (COMET), Stevens-Johnson syndrome (SJS)

\section{Introduction}

Limbal stem cells are essential for maintaining the transparency and clarity of the cornea, as these cells are self-regenerating and allow renewal of the corneal

Correspondence: Dr. Safinaz Mohd Khialdin, Department of Ophthalmology, 9th Floor, Clinical Block, Universiti Kebangsaan Malaysia Medical Centre, Jalan Yaacob Latiff, 56000 Cheras, Kuala Lumpur, Malaysia.

E-mail: drsafinaz 1978@yahoo.com.my 
epithelium. They are thought to reside at the basal layers of the corneal epithelium and limbus.

When limbal stem cells are damaged, there will be migration of conjunctiva epithelial cells to the ocular surface, hence causing neovascularization and loss of corneal clarity. The causes of LSCD can be generally divided into primary or congenital, such as aniridia and ectodermal dysplasia, and secondary or acquired, such as chemical injury, Stevens-Johnson syndrome (SJS), and ocular cicatricial pemphigoid. ${ }^{1}$ We report six cases of clinically evident severe LSCD who underwent cultivated oral mucosa epithelium transplantation COMET: four cases of chemical injury, one case of SJS, and one of acne rosacea, respectively. Their best corrected postoperative visual acuity was evaluated.

\section{Case reports}

\section{Case 1}

A 46-year-old healthy Malay man presented with history of severe acid injury to both eyes ten years ago. He was completely blind in the right eye and had counting finger vision in the left eye. Examination revealed bilateral symblepharon and almost total corneal vascularisation with pannus. There was poor cornea wettabilty in both his eyes. He underwent staged procedure of left eye COMET, followed by deep anterior lamellar keratoplasty (DALK) four months later (Fig.1). At three months following corneal transplant, the best corrected visual acuity (BCVA) had improved tremendously to 6/15. He developed cataract a year later, which brought down his vision to counting finger. After a successful cataract surgery and intraocular lens implant, he achieved 6/12 vision in the left eye. He was followed up for a duration of four years.

\section{Case 2}

A 37-year-old healthy Chinese man presented with poor vision in his left eye after chemical injury to the affected eye one year earlier. On presentation, vision in the left eye was hand movement and right eye vision was 6/6. Examination revealed inferior symblepharon with total corneal scarring and vascularisation of the left eye. There were poor details of anterior segment and beyond. He underwent left eye COMET followed by an uneventful penetrating keratoplasty (PK) with amniotic membrane transplantation (AMT) five months post COMET (Fig. 2). Postoperatively, his left BCVA improved significantly to $6 / 12$ at ten months post PK with no evidence of graft rejection. His follow-up duration was one year.

\section{Case 3}

A 44-year-old healthy Chinese man presented with right eye poor vision following one-month history of acid splash to his right eye. On examination, the visual acuity 


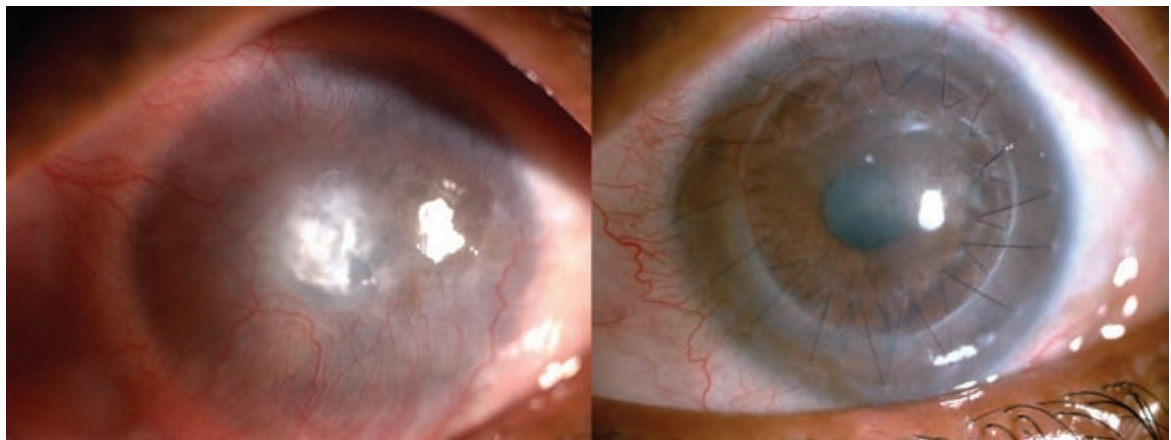

Fig. 1. Pre- and postoperative images of Case 1, where the patient underwent COMET followed by DALK. There was an improvement in corneal clarity.

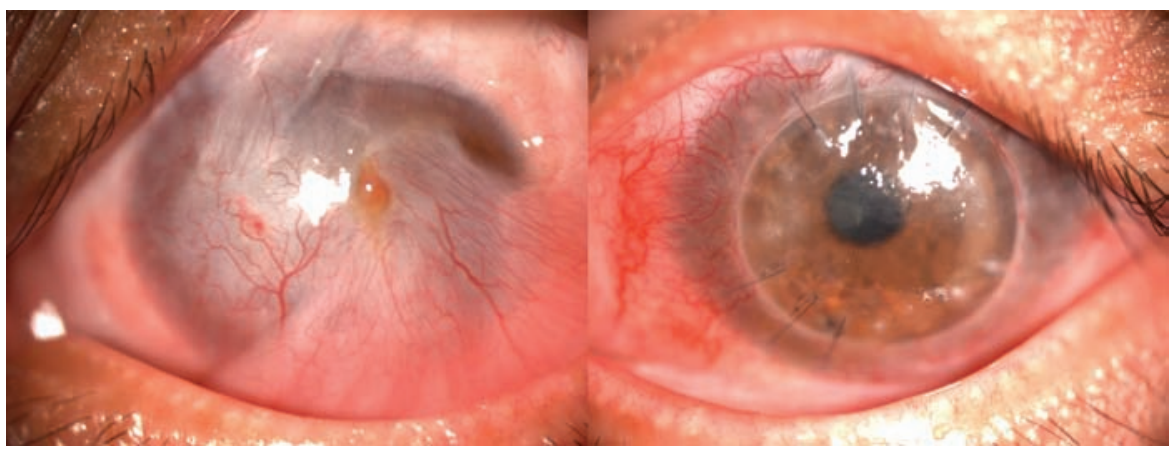

Fig. 2. Pre- and postoperative images of Case 2, where the patient underwent COMET followed by PK. The central cornea button remained clear with no evidence of rejection.

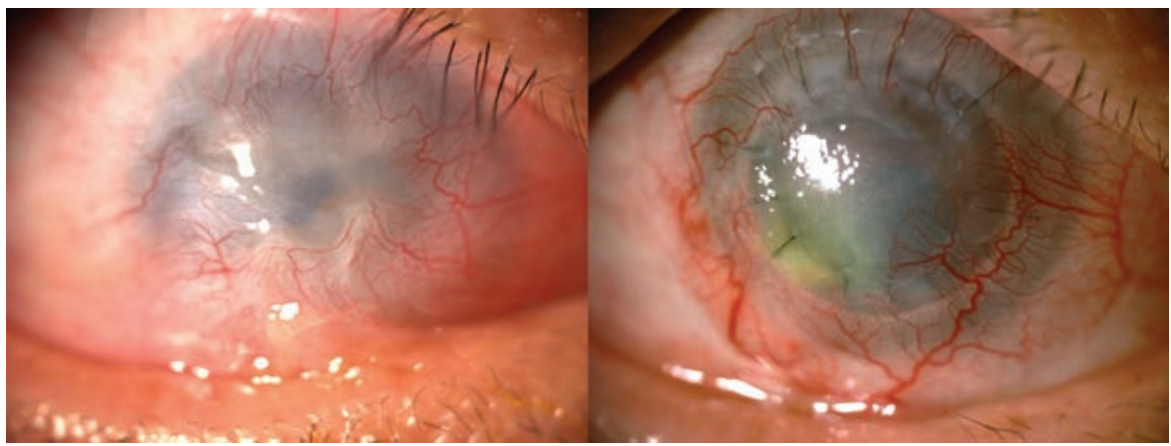

Fig.3. Pre- and postoperative images of Case 3, where the patient underwent COMET followed by PK. There was presence of vascularisation and a small persistent epithelial defect. 


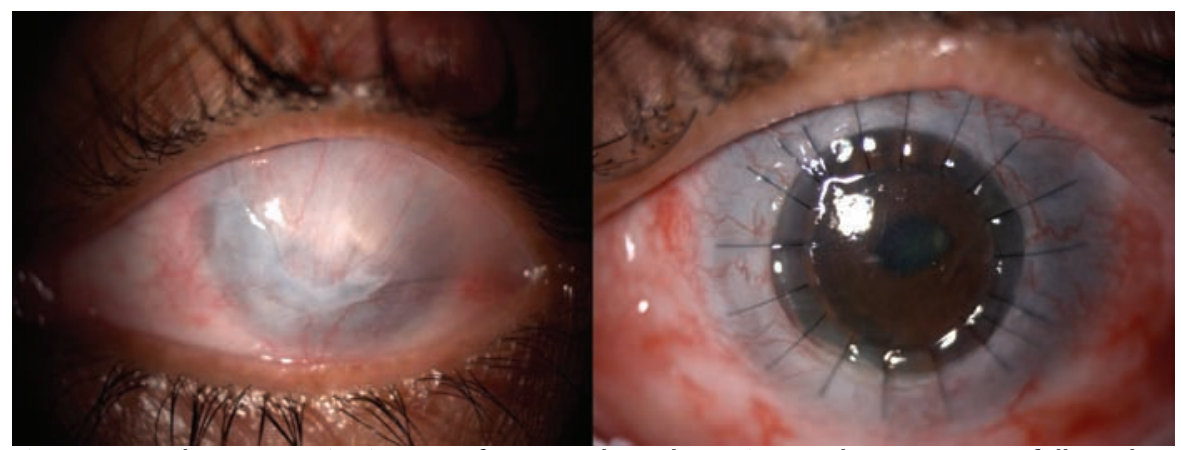

Fig. 4. Pre- and postoperative images of Case 4, where the patient underwent COMET followed by PK. There was an improvement in corneal clarity and ocular surface.

in his right eye was counting fingers. Ocular examination revealed right inferior symblepharon with total cornea epithelial defect and severe limbal ischaemia. One year post injury, he underwent right eye COMET, followed by PK with cataract extraction and intraocular lens implantation seven months post COMET (Fig. 3). Visual acuity at three-months postoperatively was hand movement with failed corneal epithelial healing. At five months post PK, he developed acute graft rejection which was treated with intensive steroids. However, his vision did not improve much and remained at counting fingers at three feet. During the last review, there was presence of heavy vascularisation and a small persistent epithelial defect of the cornea. His follow-up duration was 4 years.

\section{Case 4}

A 44-year-old healthy Malay man presented with long standing bilateral poor vision. He sustained chemical injury to both eyes with liquid ammonia 20 years ago. His vision was hand movement bilaterally. Ocular examination showed total limbal stem cell failure bilaterally and densely opaque cornea with $360^{\circ}$ vascularisation. There was loss of iris details. However, there was good and stable tear film property in both his eyes. He underwent left eye COMET in November 2014 and PK with AMT five months post COMET (Fig. 4). His postoperative visual acuity improved to $6 / 36$. This was attributed to the presence of persistent epithelial defect. However, his vision dropped further due to cataract formation and presence of corneal vascularisation. He was under follow-up for a period of two years.

\section{Case 5}

A 58-year-old Chinese female presented with progressive poor vision in both eyes for one-year duration. She always had problem with recurrent facial acne, but never sought medical attention for this problem. Her visual acuity at presentation was $6 / 60 \mathrm{OD}$ and counting finger OS. Ocular examination showed bilateral severe 


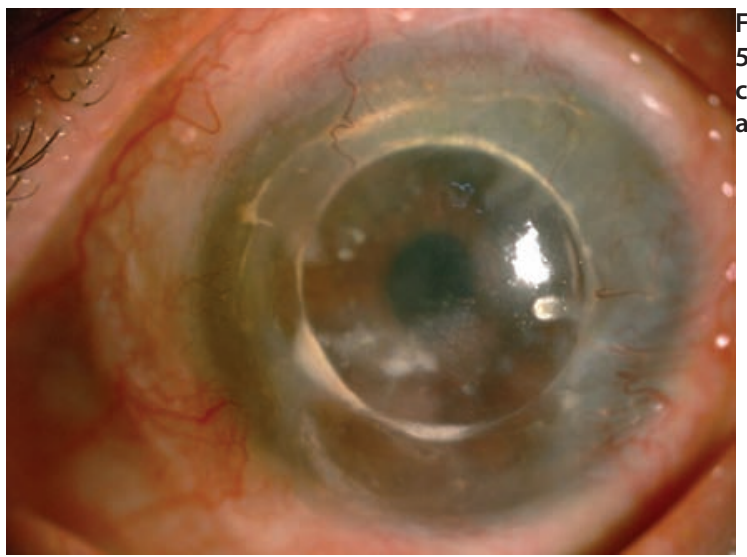

Fig. 5. Postoperative image of Case 5 showing clinical improvement in cornea epitheliopathy after DALK and COMET.

corneal scarring with poor cornea wettability and eyelid telangiectasia. There were bilateral sectoral symblepharon and vascularisation on the superior cornea. A diagnosis of ocular rosacea was given. Her right eye's condition improved after a conjunctival epitheliectomy and her right BCVA improved to 6/9.5. She underwent left eye uneventful superficial keratectomy followed by DALK with AMT five months later. Postoperatively, she developed total LSCD with vision of 6/60. In view of the total LSCD, she had COMET done one year after her DALK (Fig. 5). Unfortunately, her left vision remained at counting fingers due to cornea vascularisation with scarring. During her last ocular examination, there was improvement in the tear film with clinical improvement in cornea epitheliopathy. Her follow-up duration was seven years.

\section{Case 6}

A 59-year-old Chinese man presented with left poor vision for two years. He had history of SJS with ocular involvements secondary to gout medications.

Visual acuity was 6/9 OD and hand motion OS. Ocular examination showed superior symblepharon with loss of limbal stem cell superiorly of the right eye. A similar but denser symblepharon with total loss of limbal stem cells and significant scarring was noted in the left eye. He came back two years later with profound drop in vision to counting fingers in his right eye. Left vision was perception to light. He underwent uneventful bilateral COMET (Fig. 6). However, his BCVA was not much improved, due to presence of bilateral significant vascularisation and left cornea scarring. A second bilateral COMET was performed one year after the first surgery. Unfortunately, his vision did not improve much, with BCVA of hand movement, as both corneas remained hazy with presence of vascularisation. He was not keen on further corneal transplants. His follow-up duration was five years. 


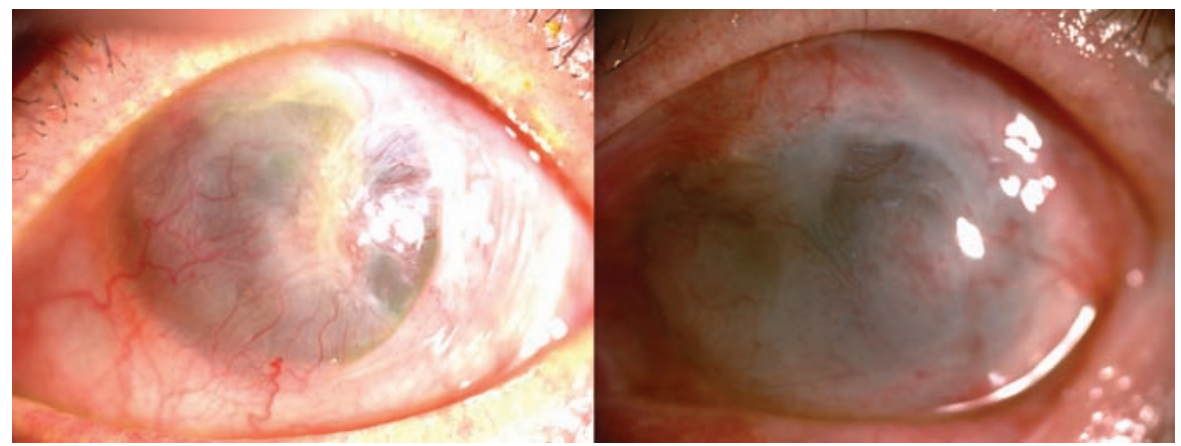

Fig. 6. Pre- and postoperative images of Case 6. The cornea remained hazy with presence of vascularisation despite undergoing COMET twice.

\section{Cultivation of oral mucosal epithelial cells transplantation with amniotic membrane-based sheets procedure}

The stages involved in COMET include harvesting and cultivating the buccal mucosa on the amniotic membrane (AM), followed by transplantation of the cells.

The buccal mucosa biopsy was obtained with the patients' consent. The buccal mucosa was sterilized and a $5 \mathrm{~mm}$ diameter tissue was collected. The tissue was then packed and transported under room temperature to the laboratory.

All cell preparation was done in a Current Good Manufacturing Practice (cGMP) accredited laboratory. The collected sample was placed on top of an AM which served as a base for the buccal mucosa culture. These cells were moistened with Defined Keratinocyte-Serum-Free Medium (SFM) (Gibco). Next, $100 \mathrm{U} / \mathrm{ml}$ of penicillin, $100 \mu \mathrm{g} / \mathrm{ml}$ of streptomycin, and $0.25 \mu \mathrm{g} / \mathrm{ml}$ of amphotericin were added. The cells were incubated in $5 \% \mathrm{CO} 2$ incubator at $37^{\circ} \mathrm{C}$ for about six to eight weeks.

Once the cells had reached confluency and covered the entire surface area of the $\mathrm{AM}$, they were transported back to the transplantation site under room temperature. Before they were transplanted onto the patient's eye, they were taken for bacterial and fungal infection testing. The last stage was either a standard procedure of LK or PK.

\section{Discussion}

LSCD is a condition where the limbal stem cells are unable to regenerate to protect the corneal epithelium. ${ }^{2,3}$ It remains a challenge to treat LSCD as there is absence of limbal stem cells to ensure proper epithelial healing and integrity of the ocular surface. Limbal stem cells can be either autografts, allografts, or cadaveric. ${ }^{4,5}$ Treatment of unilateral LSCD may include limbal autografts, cultivated limbal epithelial transplantation (CLET), or simple limbal epithelial transplantation (SLET) from the 
healthy fellow eye. However, CLET is dependent on cultivation conditions and does not show promising results in eyes with bilateral ocular surface abnormalities, such as SJS. ${ }^{4}$ SLET is a novel and easy procedure of transplanting a strip of healthy limbal tissue using an AM. As this technique requires less donor tissue and does not need a laboratory for cell expansion, it is a simple yet effective method in treating unilateral LSCD. ${ }^{6}$

In bilateral cases, the option of allograft limbal transplant from a cadaver, a family member, or COMET may be considered. ${ }^{7,8}$ By cultivating the patient's own oral mucosal epithelial cells and transplanting onto the diseased ocular surface, COMET is believed to show promising results. ${ }^{8-10}$ The study by Nishida et al. suggested that COMET may be effective to restore the ocular surface and restore vision in patients with bilateral LSCD. ${ }^{8}$ The advantages of COMET are the suitability for patients with bilateral LSCD and lack of long-term use of immunosuppresants. ${ }^{9}$ Several studies have shown that COMET combined with PK may improve graft survival and corneal clarity. ${ }^{11}$ In this study, COMET was the mainstay of treatment for patients with bilateral LCSD.

In the present case series, all the patients were followed up for more than one year. Half of them had an improvement in BCVA, with two eyes obtaining $6 / 12$ vision. In these cases, the LSCD cases were secondary to chemical injury. The improvement in vision was stable throughout the four-year follow up. The pathophysiological events that may influence the final outcome of the vision in chemical injury depend on the severity of the limbal stem cell injury and the extent of penetration of the chemical intraocularly. ${ }^{12}$ We believe that this group fared comparatively better as the insult was a one-off event which did not lead to ongoing inflammation. The six cases are summarized in Table 1.

Table 1. A summary of case series of COMET

\begin{tabular}{|l|l|l|l|l|l|l|}
\hline Case & $\begin{array}{l}\text { Initial } \\
\text { Vision }\end{array}$ & $\begin{array}{l}\text { Final } \\
\text { Vision }\end{array}$ & Indication & $\begin{array}{l}\text { Type of } \\
\text { Surgery }\end{array}$ & $\begin{array}{l}\text { Reason of } \\
\text { poor vision (if } \\
\text { any) }\end{array}$ & $\begin{array}{l}\text { Follow-up } \\
\text { duration }\end{array}$ \\
\hline 1 & CF & $6 / 12$ & $\begin{array}{l}\text { Chemical } \\
\text { injury }\end{array}$ & $\begin{array}{l}\text { COMET }+ \\
\text { DALK }\end{array}$ & nil & 4 years \\
\hline 2 & HM & $6 / 12$ & $\begin{array}{l}\text { Chemical } \\
\text { injury }\end{array}$ & $\begin{array}{l}\text { COMET } \\
+ \text { PK }\end{array}$ & nil & 1 year \\
\hline 3 & CF & CF & $\begin{array}{l}\text { Chemical } \\
\text { injury }\end{array}$ & $\begin{array}{l}\text { COMET } \\
+ \text { PK }\end{array}$ & $\begin{array}{l}\text { Acute graft } \\
\text { rejection }\end{array}$ & 4 years \\
\hline 4 & HM & $6 / 36$ & $\begin{array}{l}\text { Chemical } \\
\text { injury }\end{array}$ & $\begin{array}{l}\text { COMET } \\
+ \text { PK }\end{array}$ & $\begin{array}{l}\text { Persistent } \\
\text { epithelial } \\
\text { defect }\end{array}$ & 2 years \\
\hline
\end{tabular}


Oh, Zahidin, Kalthum et al.

\begin{tabular}{|l|l|l|l|l|l|l|}
\hline Case & $\begin{array}{l}\text { Initial } \\
\text { Vision }\end{array}$ & $\begin{array}{l}\text { Final } \\
\text { Vision }\end{array}$ & Indication & $\begin{array}{l}\text { Type of } \\
\text { Surgery }\end{array}$ & $\begin{array}{l}\text { Reason of } \\
\text { poor vision (if } \\
\text { any) }\end{array}$ & $\begin{array}{l}\text { Follow-up } \\
\text { duration }\end{array}$ \\
\hline 5 & CF & $6 / 60$ & $\begin{array}{l}\text { Ocular } \\
\text { rosacea }\end{array}$ & $\begin{array}{l}\text { DALK+ } \\
\text { COMET }\end{array}$ & $\begin{array}{l}\text { Cornea vascu- } \\
\text { larization with } \\
\text { scarring }\end{array}$ & 7 years \\
\hline 6 & $\begin{array}{l}\text { RV: } \text { CF } \\
\text { LV: PL }\end{array}$ & $\begin{array}{l}\text { RV: HM } \\
\text { LV: HM }\end{array}$ & $\begin{array}{l}\text { Stevens- } \\
\text { Johnson } \\
\text { syndrome }\end{array}$ & $\begin{array}{l}\text { COMET } \\
\text { twice }\end{array}$ & Failed COMET & 5 years \\
\hline
\end{tabular}

We observed patients with SJS did worse than those with chemical injury, as evidenced by persistent extensive vascularisation and scarring after COMET. Previous studies also showed similar findings. ${ }^{13-15}$ It is likely that SJS eyes have a poorer preoperative ocular surface, poor tear function, and metaplasia of the conjunctival epithelium as well as lid margin abnormalities and keratinisation.

We also noted that surgical success depends on the severity and chronicity of the disease. In the group of patients with chemical injury, the outcome of surgery in Case 4 was the worst as it started with a Grade 4 chemical injury of 20 years of duration. We believe that the chronicity of the disease leads to total loss of limbal and corneal epithelium. In his eye, there was epithelization of the cornea by the conjunctival epithelium. The clinical features of LSCD chronicity include severe pannus formation and cornea vascularisation, which was present in his eyes. Corneal vascularisation and low-grade inflammation are the key factors in determining corneal graft survival. Although COMET helped reduce the amount of corneal vascularity, it did not totally eliminate the presence of active vessels.

Most patients in our series managed to achieve navigational vision following their surgery. They reported independence in daily tasks, which helped to boost their confidence and improve family relationships through facial recognition. Therefore, COMET has been shown to improve the ocular surface in patients with secondary LSCD, as this procedure reduces corneal scarring and vascularity. In particular, it appears to improve corneal transplant outcomes in patients with ocular chemical injury in our series. The final visual improvement is largely affected by the degree of initial insult and severity of ocular surface disease. Careful patient selection and proper counselling is of utmost importance to ensure realistic expectations to the outcome of surgery.

\section{Acknowledgements/Disclosure}

This research did not receive any specific grant from funding agencies in the public, commercial, or not-for-profit sectors. The authors have no financial disclosures. 


\section{References}

1. Schwartz GS, Holland EJ. Classification and staging of ocular surface disease. In: Krachrner JH, Mannis MJ, Holland EJ, eds. Cornea. 3rd ed. Vol 2. Philadelphia: Elsevier/Mosby; 2011:1713-1720.

2. Ahmad S, Osei-Bempong C, Dana R, Jurkunas U. The culture and transplantation of human limbal stem cells. Journal of cellular physiology. 2010;225(1):15-19. doi:10.1002/jcp.22251.

3. Sangwan VS. Limbal stem cells in health and disease. Bioscience reports. 2001;21(4):385-405.

4. Shimazaki J, Higa K, Morito F, et al. Factors influencing outcomes in cultivated limbal epithelial transplantation for chronic cicatricial ocular surface disorders. Am J Ophthalmol. 2007;143(6):945-953. doi:10.1016/j.ajo.2007.03.005.

5. de Araujo AL, Gomes JÁ. Corneal stem cells and tissue engineering: Current advances and future perspectives. World J Stem Cells. 2015;7(5):806-14. doi:10.4252/wjsc.v7.i5.806.

6. Sangwan VS, Basu S, MacNeil S, Balasubramanian D. Simple limbal epithelial transplantation (SLET): a novel surgical technique for the treatment of unilateral limbal stem cell deficiency. $\mathrm{Br} J$ Ophthalmol. 2012;96:931-934.

7. Fernandes M, Sangwan VS, Rao SK, et al. Limbal stem cell transplantation. Indian J Ophthalmol. 2004;52(1):5-22.

8. Nishida K, Yamato M, Hayashida Y, et al. Corneal reconstruction with tissue-engineered cell sheets composed of autologous oral mucosal epithelium. N Eng J Med. 2004;351(12):1187-1196 doi:10.1056/NEJMoa040455

9. Hirayama M, Satake Y, Higa K, Yamaguchi T, Shimazaki J. Transplantation of cultivated oral mucosal epithelium prepared in fibrin-coated culture dishes. Invest Ophthalmol Vis Sci. 2012;53(3):1602-1609. doi:10.1167/iovs.11-7847.

10. Kinishita S, Nakamura T. Development of cultivated mucosal epithelial sheet transplantation for ocular surface reconstruction. Artif Organs. 2004;28(1):22-27.

11. Ozdemir O, Tekeli O, Ornek K, Arslanpence A, Yalcindag NF. Limbal autograft and allograft transplantations in patients with corneal burns. Eye. 2004;18(3):241-248

12. Wagoner, Michael D. Chemical injuries of the eye: current concepts in pathophysiology and therapy. Surv Ophthalmol. 1997;41(4):275-313.

13. Shimazaki J, Aiba M, Goto E, Kato N, Shimmura S, Tsubota K. Transplantation of human limbal epithelium cultivated on amniotic membrane for the treatment of severe ocular surface disorders. Ophthalmology. 2002;109:1285-1290.

14. Samson CM, Nduaguba C, Baltatzis S, Foster CS. Limbal stem cell transplantation in chronic inflammatory eye disease. Ophthalmology. 2002;109:862-868

15. Tsubota K, Satake Y, Kaido M, et al. Treatment of severe ocular-surface disorders with corneal epithelial stem-cell transplantation. N Engl J Med. 1999;340:1697-1703. 